\title{
The Influence of Urban Haze Pollution on Urban Shrinkage in China - An Analysis of the Mediating Effect of the Labour Supply
}

Xiaohong Liu ( $\square$ amylxhong@163.com )

Nanjing Xiaozhuang University https://orcid.org/0000-0003-3704-5897

\section{Research Article}

Keywords: haze pollution, urban shrinkage, labour supply, mediation effect, SYS-GMM, China

Posted Date: April 28th, 2021

DOI: https://doi.org/10.21203/rs.3.rs-386676/v1

License: (1) This work is licensed under a Creative Commons Attribution 4.0 International License.

Read Full License

Version of Record: A version of this preprint was published at Environmental Science and Pollution Research on July 5th, 2021. See the published version at https://doi.org/10.1007/s11356-021-15025-8. 

(2) . 42

The influence of urban haze pollution on urban shrinkage in China - An analysis of the mediating effect of the labour supply

\section{Xiaohong Liu}

Business school of Nanjing Xiaozhuang University, Nanjing, 211171, amylxhong@163.com China

*Corresponding author. Xiaohong Liu , E-mail: amylxhong@ 163.com Acknowledgments

This study was supported by the Philosophy and society project of universities in Jiangsu Province (No.2020SJA0492).

\section{Author Contributions}

Xiaohong Liu conceived the study idea and designed the research framework, wrote the manuscript.

18

(18)

(1)

1

3

7

8

0

1
39 
The influence of urban haze pollution on urban shrinkage in China - An analysis of the mediating effect of the labour supply

Abstract: Panel data of 234 cities in China from 2011 to 2018 is used to measure the urban shrinkage index. $\mathrm{PM}_{2.5}$ is used as an indicator of haze pollution, and labour supply is the mediator. On this basis, the influence mechanism of haze pollution on urban shrinkage is analysed theoretically. Next, using the dynamic panel model and the mediating effect model, we empirically examine the impact of urban shrinkage on haze pollution and the mediating effect of labour supply. The main findings are as follows: haze pollution increases the degree of urban shrinkage, and labour supply plays a regulatory role in the process of haze pollution affecting urban shrinkage. According to our research, pertinent policies and suggestions are proposed to reduce both urban shrinkage and haze pollution.

Key words: haze pollution; urban shrinkage; labour supply; mediation effect; SYS-GMM; China

\section{Introduction}

China's urbanisation has been rapid since the reform and opening-up. In 2019, the proportion of the urban population was as high as $60.6 \%$. Most of China's cities have had obvious spatial expansion, which has strongly promoted China's economic growth. However, some cities are shrinking. The "Key Tasks for New Urbanization Construction in 2019" issued by the China Development and Reform Commission first proposed the concept of a "shrinkage city". This paper proposes a new type of urbanisation strategy, which uses promoting human urbanisation as the core and improving quality as the main guidance. The shrinkage of small and medium-sized cities should be thin and strong, change the inertia in incremental planning thinking, and strictly control the increment. Additionally, since 2013, China's urban haze pollution has occurred frequently and seriously threatens the steady operation of the social economy. This persistent problem of haze pollution in Chinese cities harms public health and China's international image. The Chinese government has said about the problem of haze pollution that "green water and green mountains are golden mountains and silver mountains", and implemented policies to decrease pollution. 
Thus, what is the impact of urban haze pollution on urban shrinkage, and what is the mediating effect of haze pollution on urban shrinkage in China? The literature has not answered these two questions. Thus, this paper aims to answer these questions by investigating the impact of haze pollution on urban shrinkage and providing suggestions for the governance of haze pollution and urban shrinkage.

\section{Literature review}

The research on urban shrinkage has focused on the measurement and causes of urban shrinkage. The measurement of urban shrinkage mainly adopts single index analysis as a method. Among them, the population size indicator is the most commonly used indicator. For example, Oswalt et al. (2006) regarded the loss of population accounting for more than $10 \%$ of the total population or the average annual population loss rate greater than $1 \%$ as the threshold value for judging urban shrinkage. Schilling and Logan (2008) used the standard of 40 years of continuous population loss greater than $25 \%$ to identify shrinking cities. There are also multi-dimensional indicator methods. The major indicators include economic indicators, spatial statistics, geographic landscape detection, and new data (Reis et al., 2015). The causes of urban shrinkage include economic, social, and environmental factors (Reckien and Martinez, 2011; Martinez F et al., 2016). China is characterised by the influx of many individuals from the central and western regions and small and medium-sized cities into the developed eastern cities. There is also a strong correlation between the changing factors of population structure and urban shrinkage in China. The imbalance of regional economic development caused by globalisation, ageing, and an urban administrative hierarchy with Chinese characteristics are the major causes of urban shrinkage in China.

The literature on haze pollution in Chinese cities is abundant. Many documents have conducted in-depth discussions on the influencing factors of urban haze pollution, which can be divided into two aspects: natural factors and socio-economic factors. Regarding natural factors, many studies have shown that temperature (Mazeikis, 2013), precipitation (Tai et al., 2010), wind speed (Lee et al., 2015), relative humidity (Whiteman et al., 2014), and air pressure (Li et al., 2014) play an 
important role in the formation process of haze pollution. Haze pollution is caused by natural phenomena and human economic activities. Therefore, many scholars have investigated the influencing factors of urban haze pollution from the perspective of social and economic development, for example, urbanisation (Akimoto, 2003; Xu and Lin, 2016), industrial structure (Cheng K., 2019), economic development (Dong et al., 2019), transportation (Fang et al., 2016), and environmental regulation (Li et al., 2019).

The aforementioned documents laid the foundation for the writing of this article, but other aspects are worthy of further in-depth discussion: First, in terms of the influencing factors of urban shrinkage, haze pollution has been rarely studied as an important influencing factor of urban shrinkage. Second, the literature has investigated the impact of haze pollution on health and economic development quality, but studies on the effect of haze pollution on urban shrinkage have been relatively rare. Third, labour supply has rarely been used as a mediator to analyse the effect of haze pollution.

Based on the aforementioned research, this paper intends contributing the following expansion: First, the influence of haze pollution on urban shrinkage is discussed in depth theoretically, enriching the literature on the influencing factors of urban shrinkage and haze pollution. Second, labour supply is used as a mediator to analyse its transmission effect in the process of haze pollution affecting urban shrinkage. Third, to control endogenous problems, a dynamic econometric model is used to empirically test the impact of haze pollution on urban shrinkage and the mediating effect of labour supply.

\section{Theoretical analysis and research hypothesis}

Haze pollution, an atmospheric phenomenon in which smoke particles gather in relatively dry air (Friedlander and Marlow, 1977), negatively affects human health, transportation, national economic operations, and residents' lifestyles (Li and Zhang, 2014; Shi et al., 2016). $\mathrm{PM}_{2.5}$ is the main component in haze pollution that harms human health and can enter the human circulatory system and cause respiratory tract inflammation and other diseases (Feng et al., 2015). Additionally, when haze pollution 
occurs, visibility decreases, causing visual deviations that cause, for example, traffic accidents.

Haze also has economic effects at the country level. For example, Quah and Boon (2003) demonstrated that the economic loss due to the $\mathrm{PM}_{10}$ in haze pollution in Singapore was approximately US\$3.662 billion. Haze also affects individuals' lifestyles. For example, the schools in Nanjing and other cities close when haze pollution is serious and some have built indoor sports halls to protect students from the health hazards of haze pollution. At present, China's market economy is improving daily, and labour employment has great autonomy. In particular, some highly educated members of the labour force, in addition to the requirements for positions and salary, are paying more attention to the living environment of the city, such as air quality. Therefore, when haze pollution occurs in a city, some qualified residents, such as high-quality and high-tech residents, will flow out of the city by changing their working places. The outflow of urban residents has led to a decrease in the labour supply, industrial recession, and space vacancy, resulting in urban shrinkage. Based on this phenomenon, our proposed hypotheses are as follows:

Hypothesis 1: Haze pollution will increase the degree of urban shrinkage.

Hypothesis 2: Labour forces play a mediating role in the process of haze pollution affecting urban shrinkage.

\section{Methodology and data}

\subsection{Econometric model}

To test Hypothesis 1, the following economic model is established:

$$
C S_{i t}=\alpha_{0}+\beta_{0} \ln P M_{2.5 i t}+\beta_{1}\left(\ln P M_{2.5 i t}\right)^{2}+\sum \gamma_{j} x_{i j t}+\mu_{i}+\lambda_{t}+\varepsilon_{i t}
$$

In formula (1), $i$ is the city, $t$ is the year, $P M_{2.5}$ is the core explanatory variable haze pollution, and $x_{i j t}$ is a series of control variables, including the proportion of tertiary industry, urban greening, and economic development. $\mu_{i}$ is the unobservable regional individual effect, $\lambda_{t}$ is the time effect, $\varepsilon_{i t}$ is a random interference item that obeys a normal distribution, and $\mu_{i}$ is not related to $\varepsilon_{i t}$ 
Studies have shown that the static panel model may have missing variables and endogenous problems; thus, the following dynamic panel model is established:

$$
C S_{i t}=\alpha_{0}+\alpha_{1} C S_{i, t-1}+\beta_{0} \ln P M_{2.5 i t}+\beta_{1}\left(\ln P M_{2.5 i t}\right)^{2}+\sum \gamma_{j} x_{i j t}+\mu_{i}+\lambda_{t}+\varepsilon_{i t}
$$

$C S_{i, t-1}$ is the first-order lag of urban shrinkage.

The dynamic panel model of formula (2) incorporates the explanatory variable city shrinkage as an explanatory variable into the model, which can control the endogeneity and increase the accuracy of the estimation result.

After the establishment of Hypothesis 1, Hypothesis 2 is established according to the mediation model. Mediation refers to the influence of an explanatory variable (X) on the explained variable (Y) through a third-party variable transfer called mediation (MacKinnon et al., 2000). The mediation model has been often used in environmental and other research fields (Dubey et al., 2019). The causal step method has been the most commonly used to test the mediating effect (Baron and Kenny, 1986; Chen et al., 2020)

$$
\begin{aligned}
& Y=c X+e_{i} \\
& M=a X+e_{i} \\
& Y=c^{\prime} X+b M+e_{i}
\end{aligned}
$$

The first step is to check whether the coefficient $\mathrm{c}$ in the coefficient formula (3) is significant. The second step is to check whether the coefficient a in formula (4) is significant. The third step is to check whether the coefficient and b in formula (5) are significant. If $c, a$, and $b$ are all significant, yet $c^{\prime}$ is not significant or significant but the coefficient value decreases, $M$ is a mediator.

$$
\begin{aligned}
& \ln L S_{i t}=\alpha_{0}+\alpha_{1} \ln L S_{i, t-1}+\beta_{0} \ln P M_{2.5 i t}+\sum \gamma_{j} x_{i j t}+\mu_{i}+\lambda_{t}+\varepsilon_{i t} \\
& C S_{i t}=\alpha_{0}+\alpha_{1} C S_{i, t-1}+\beta_{0} \ln P M_{2.5 i t}+\beta_{1}\left(\ln P M_{2.5 i t}\right)^{2}+\beta_{2} \ln L S_{i t}+\sum \gamma_{j} x_{i j t}+\mu_{i}+\lambda_{t}+\varepsilon_{i t}
\end{aligned}
$$

To test Hypothesis 2, formulas (6) and (7) are established. $\operatorname{lnLS}$ is the logarithm of labour supply. In the mediating test, CS is the explained variable, $\operatorname{lnLS}$ is the mediator $M$, and $\ln \mathrm{PM}_{2.5}$ is the explanatory variable $X$. Formula (2) corresponds to 
formula (3). Formulas (6) and (7) correspond to formulas (4) and (5).

\subsection{Data description}

This paper uses the data from 2011 to 2018 in 234 cities in China as the research sample. The original data are from China's Urban Statistics Yearbook and China's Urban Construction Yearbook from 2010 to 2019, as well as the statistical yearbooks and environmental bulletin of 234 cities in corresponding years. The missing value is filled through interpolation.

\subsection{Variables' selection}

\subsubsection{Measurement of urban shrinkage}

Urban shrinkage is the explained variable of this article. According to Murdoch III (2018), formula (8) is used to measure urban shrinkage (CS).

$$
C S_{i t}=-\ln \left(\frac{P O P_{i t}}{P O P_{i 2010}}\right)
$$

In formula (8), $\mathrm{POP}_{\mathrm{it}}$ represents the population of the urban area during $\mathrm{t}$.

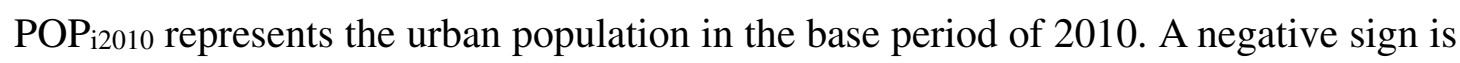
added to the formula so that the greater the loss of population, the greater the urban shrinkage. Without the negative sign, this phenomenon would be reversed.

The descriptive statistics of each variable are presented in Table 1.

\subsubsection{Haze pollution}

In this paper, $\mathrm{PM}_{2.5}$ is used to refer to haze pollution, and the unit is $\mu \mathrm{g} / \mathrm{m}^{3} . \mathrm{PM}_{2.5}$ has been monitored in some cities in China since the end of 2012. In January 2013, the new "Ambient Air Quality Standard" was implemented, and $\mathrm{PM}_{2.5}$ concentration data in 74 cities were released. Therefore, the $\mathrm{PM}_{2.5}$ data of 234 cities from 2011 to 2016 were obtained from the Battelle Institute and the international geoscience information network centre of Columbia University. The grid data of annual mean $\mathrm{PM}_{2.5}$ was measured by satellite borne equipment, and then $\mathrm{PM}_{2.5}$ concentration value was obtained by ArcGIS software (Van donkelaar, 2010). The 2017 data are from the $\mathrm{PM}_{2.5}$ concentration ranking of 365 cities in China released by Greenpeace. The 2018 data comes from the statistical yearbooks of each city. 4.3.3. Mediator and control variables 
The mediator is labour supply (LS), expressed by the number of employees at the end of the year, and the unit is 10,000. Control variables include the proportion of the tertiary industry (TI), urban greening (GR) and economic development (GDP). The proportion of the tertiary industry is expressed by the proportion of the added value of the tertiary industry in GDP, and the unit is \%; urban greening is expressed by the rate of green space in the built-up area, and the unit is \%. Economic development is represented by the per capita real GDP of each city. Taking 2011 as the base year, the GDP per capita index is used to convert it into constant price GDP.

The descriptive statistics of each variable are shown in Table 1.

Table 1

Descriptive statistics of variables.

\begin{tabular}{ccccccc}
\hline Variable & Observations & Mean & Median & Max & Min & Sum \\
\hline CS & 1861 & -0.1217 & -0.070 & 0.618 & -1.154 & -226.578 \\
PM $_{2.5}$ & 1861 & 40.047 & 38.000 & 86.588 & 5.343 & 74529.17 \\
LS & 1861 & 64.492 & 37.366 & 986.870 & 5.110 & 120020.6 \\
TI & 1861 & 42.840 & 39.630 & 4139.000 & 10.150 & 79726.60 \\
GR & 1861 & 36.290 & 36.800 & 56.580 & 4.780 & 67536.26 \\
GDP & 1861 & 41482.16 & 35335.81 & 406647.7 & 8877.00 & 77198295 \\
\hline
\end{tabular}

\section{Results and discussion}

\subsection{Multicollinearity test}

A Pearson correlation test was used to test whether there was multicollinearity among variables. The results are shown in Table 2. The correlation coefficients between many variables did not pass the significance test. Some variables passed the

234 significance test, but the correlation coefficients were lower than 0.45 .

\section{Table 2}

Pearson correlation test.

\begin{tabular}{ccccccc}
\hline & $\mathrm{CS}$ & $\mathrm{PM}_{2.5}$ & LS & TI & GR & GDP \\
\hline $\mathrm{CS}$ & 1 & & & & & \\
\hline
\end{tabular}




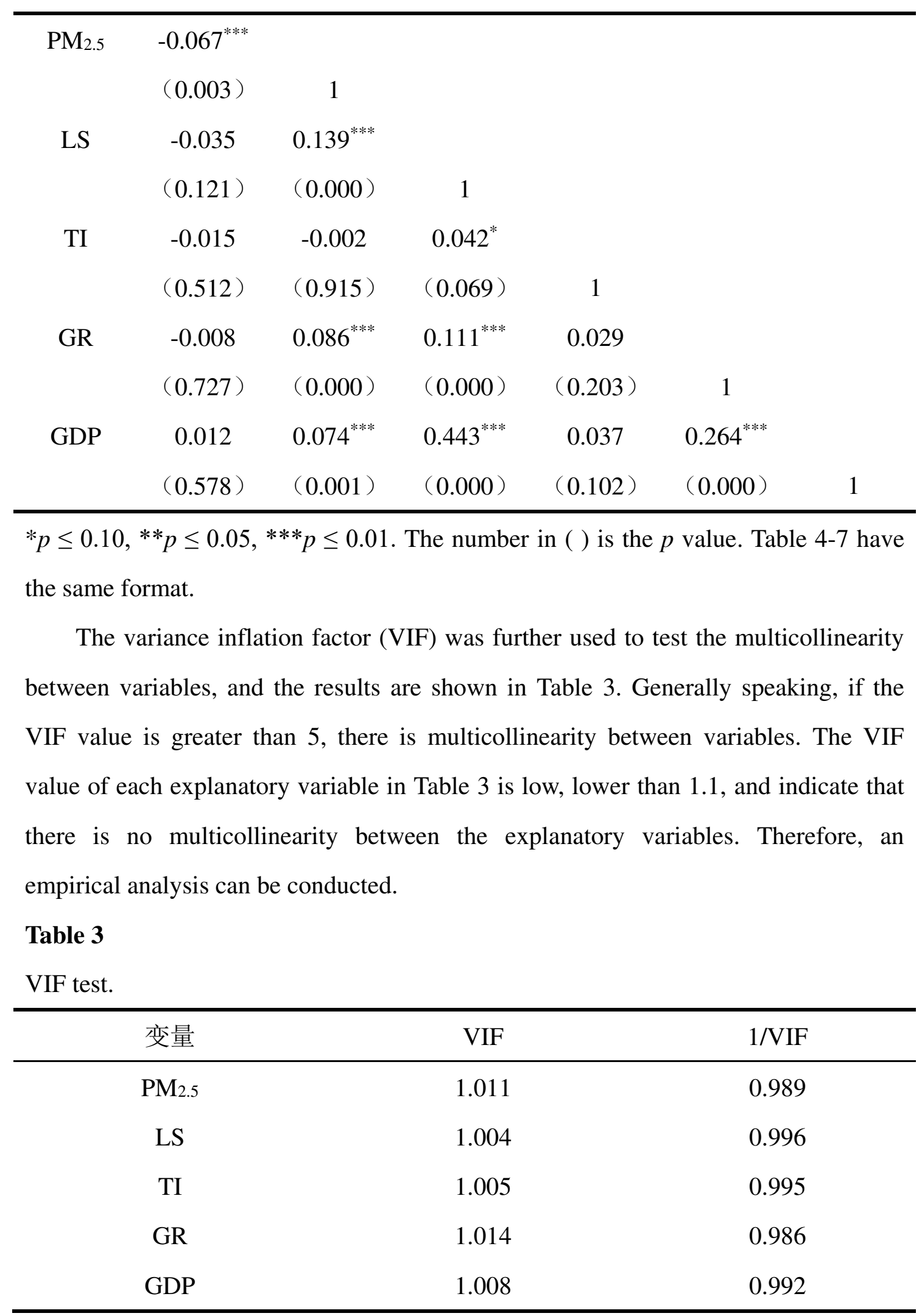

5.2. Panel unit root tests

248 To prevent false regression, unit root test should be performed on the stability of the 249 data. In this paper, ADF Fisher, PP Fisher and LLC methods are used, and the results 
are shown in Table 4. Each method shows that the level value of each variable is stable, that is, the original sequence of each variable rejects the null hypothesis and is a stationary sequence, and the next step of regression analysis can be performed.

\section{Table 4}

Results of panel unit root tests.

\begin{tabular}{cccc}
\hline & ADF-Fisher & PP-Fisher & LLC \\
\hline CS & $529.923^{* *}(0.024)$ & $552.737^{* * *}(0.004)$ & $-24.522^{* * *}(0.0000)$ \\
PM2.5 & $834.788^{* * *}(0.000)$ & $915.609^{* * *}(0.000)$ & $-17.924^{* * *}(0.000)$ \\
LS & $979.226^{* * *}(0.000)$ & $852.834^{* * *}(0.000)$ & $-57.060^{* * *}(0.000)$ \\
TI & $616.051^{* * *}(0.000)$ & $1049.610^{* * *}(0.000)$ & $-19.481^{* * *}(0.000)$ \\
GR & $770.041^{* * *}(0.000)$ & $773.805^{* * *}(0.000)$ & $-70.347^{* * *}(0.000)$ \\
GDP & $649.485^{* * *}(0.000)$ & $649.485^{* * *}(0.000)$ & $-20.819^{* * *}(0.000)$ \\
\hline
\end{tabular}

\subsection{Results for the baseline model}

To test Hypothesis 1, formula (2) is regressed. Moreover, this model is the basis for subsequent hypothesis testing and is a baseline model. Haze pollution and urban shrinkage are long-term processes, and the dynamic panel model can best reflect the relationship between them. Generalised method of moments (GMM) can effectively manage endogenous problems; thus, this paper uses this method to estimate formula (2). GMM is divided into the differential GMM model (DIFF-GMM) and system GMM model (SYS-GMM). The results are presented in Table 5. GMM requires that the residual sequence of the sample does not have second-order or higher-order autocorrelation, and the instrumental variables have strict exogeneity. Therefore, the Arellano-Bond (AR) serial correlation test and Sargan test are required for the estimation results. In DIFF-GMM and SYS-GMM, the P value of AR(1) is less than 0, and the $\mathrm{P}$ value of $\mathrm{AR}(2)$ is greater than 0.1, indicating that the residual sequence of the sample has a first-order negative correlation, but there is no second-order and above. The dynamic model has passed the correlation test.

In addition, the Sargan test is necessary to identify whether the instrumental variables are valid. The null hypothesis is that all the instrumental variables are valid. 
272 If the corresponding $\mathrm{P}$ value is greater than 0.1 , the null hypothesis is accepted at the $27310 \%$ significance level. All P values of the Sargan test are greater than 0.1 , the null 274 hypothesis is accepted, and the instrumental variables are valid. The AR and Sargan tests show that the selection of DIFF-GMM and SYS-GMM instrument variables in Table 5 is reasonable, the model identification is effective, and the estimation results are consistent and reliable. The first-order lag of urban shrinkage is significantly positive, that is, the urban shrinkage in the previous period will have a positive effect on the urban shrinkage in the next period. In addition, regarding the comparison of as -GMM and SYS-GMM, the estimation result of SYS-GMM is more effective (Blundell and Bond, 1998; Roodman, 2009). Therefore, the following discussion mainly analyses the estimation results of SYS-GMM.

Column (4) only regresses the haze pollution and the square of haze pollution, and columns (5) and (6) increase the control variables. In columns (4)-(6), the coefficient of haze pollution is positive, the coefficient of haze pollution square is negative, and both pass the significance test. This finding demonstrates an inverted U-shaped curve between haze pollution and urban shrinkage, that is, when the haze pollution increases, the degree of urban shrinkage increases. However, when the haze pollution reaches a certain point, the urban shrinkage reaches its maximum. Subsequently, an increase in haze pollution decreases urban shrinkage because the haze pollution causes the labour force, capital, and other resources to flow out of the city; the supply of labour, capital, and other resources to decrease; and buildings to become vacant. However, cities do not shrink indefinitely. When the urban shrinkage reaches a certain point, the local government will probably implement measures to reduce the degree of urban shrinkage.

Table 5

297 Estimation results of baseline model regression

\begin{tabular}{ccccccc}
\hline Variable & \multicolumn{3}{c}{ DIFF-GMM } & \multicolumn{3}{c}{ SYS-GMM } \\
\hline & $(1)$ & $(2)$ & $(3)$ & $(4)$ & $(5)$ & $(6)$ \\
L.CS & $0.9565^{* * *}$ & $0.8170^{* * *}$ & $0.8160^{* * *}$ & $0.9561^{* * *}$ & $0.9447^{* * *}$ & $0.9464^{* * *}$ \\
\hline
\end{tabular}




\begin{tabular}{ccccccc}
\hline & $(0.000)$ & $(0.000)$ & $(0.000)$ & $(0.000)$ & $(0.000)$ & $(0.000)$ \\
$\operatorname{lnPM}_{2.5}$ & $0.1453^{* * *}$ & $0.1434^{* *}$ & $0.1378^{* *}$ & $0.1128^{* * *}$ & $0.1123^{* * *}$ & $0.1027^{*}$ \\
& $(0.003)$ & $(0.020)$ & $(0.027)$ & $(0.001)$ & $(0.036)$ & $(0.095)$ \\
& $(0.002)$ & $(0.029)$ & $(0.037)$ & $(0.001)$ & $(0.043)$ & $(0.051)$ \\
$\left.\ln { }^{2} M_{2.5}\right)^{2}$ & $-0.02210^{* * *}$ & $-0.0195^{* *}$ & $-0.0188^{* *}$ & $-0.01648^{* * *}$ & $-0.0159^{* *}$ & $-0.0153^{*}$ \\
& & $-0.0546^{* * *}$ & $-0.0548^{* * *}$ & & $-0.0126^{* *}$ & $-0.0102^{*}$ \\
$\operatorname{lnGR}$ & $(0.002)$ & $(0.002)$ & & $(0.039)$ & $(0.095)$ \\
& & $-0.1172^{* * *}$ & $-0.1146^{* * *}$ & & -0.0083 & 0.0035 \\
$\operatorname{lnGDP}$ & $(0.001)$ & $(0.001)$ & & $(0.661)$ & $(0.861)$ \\
& & & -0.0111 & & & -0.0098 \\
AR (1) & 0.000 & 0.0000 & 0.0000 & 0.000 & 0.000 & 0.000 \\
AR (2) & 0.9102 & 0.9390 & 0.9283 & 0.9122 & 0.9232 & 0.9245 \\
Sargan test & 0.7590 & 0.4704 & 0.4964 & 0.4615 & 0.3500 & 0.4398 \\
\hline
\end{tabular}

298

Notes: (1)AR(1), $\mathrm{AR}(2)$ and Sargan test provide the P value of the test respectively;

(2) L1. represents the lagging period of the variable, the same as below.

5.4. Results for mediation test

Based on the aforementioned results, according to the causal step method, Hypothesis 2 is tested. Because Hypothesis 1 is true, the first step of the mediation effect test is true. Therefore, only the second and third steps are tested. Based on formula (6), we examine the impact of haze pollution on labour supply, that is, we test the second step; the results are presented in Table 6. The impact of haze pollution on the labour supply is significantly negative: haze pollution will reduce the labour supply in cities. Every $1 \%$ increase in haze pollution reduces labour supply by $1.4585 \%$, which passed the second-step test of the mediating effect.

The impact of haze pollution on the labour supply is also called environmental migration, that is, the negative impact of haze pollution on human health, transportation, and other aspects produces a "driving effect". A part of the labour force, especially the workers with higher education levels, will move from their current 
locations and find jobs in other cities to protect their and their families' health; this phenomenon reduces the labour supply.

\section{Table 6}

Result of the second step of the causal steps approach.

\begin{tabular}{cccc}
\hline Variable & $(1)$ & $(2)$ & $(3)$ \\
\hline L.lnLS & $1.0013^{* * *}(0.000)$ & $1.431^{* * *}(0.000)$ & $1.308^{* * *}(0.000)$ \\
$\operatorname{lnPM} 2.5$ & $-0.9651^{* * *}(0.004)$ & $-2.6370^{* * *}(0.001)$ & $-1.4585^{*}(0.087)$ \\
$\operatorname{lnTI}$ & $0.1691(0.328)$ & & $-0.3566^{*}(0.079)$ \\
$\operatorname{lnGR}$ & $0.8071^{* * *}(0.000)$ & $-0.1655(0.510))$ & $-0.0388(0.861)$ \\
$\operatorname{lnGDP}$ & 0.000 & $0.8106^{* * *}(0.000)$ & $0.5406^{* *}(0.015)$ \\
AR (1) & 0.122 & 0.001 & 0.006 \\
AR (2) & 0.675 & 0.308 & 0.145 \\
Sargan test & & 0.587 & 0.786 \\
\hline
\end{tabular}

Based on formula (7), the third step is used to examine the impact of the labour supply on urban shrinkage; the results are presented in Table 7. The coefficient of labour supply is significantly negative, and the coefficients of haze pollution and the square of haze pollution are greater than 0 and less than 0 , respectively, and both pass the significance test. Compared with the results in column (6) of Table 5, the coefficients of haze pollution and the square of haze pollution change from 0.1027 and -0.0153 to 0.1221 and -0.0166 , which passes the third-step test of the mediating effect.

The impact of labour supply on urban shrinkage is significantly negative, that is, an increase in labour supply reduces the degree of urban shrinkage. This finding confirms Hypothesis 2, that is, the labour supply has a significant mediating effect in the process of haze pollution affecting urban shrinkage.

As aforementioned, haze pollution causes the labour force to withdraw from the employment market and triggers urban shrinkage. Moreover, for cities with haze pollution the outflow of high-end talent, such as scientific and technological personnel, reduces technological innovation ability, slows the level of economic development, 
and aggravates the degree of urban shrinkage.

Table 7

335 Result of the third step of the causal steps approach.

\begin{tabular}{|c|c|c|c|c|}
\hline 变量 & (1) & (2) & (3) & (4) \\
\hline \multirow[t]{2}{*}{ L.CS } & $0.9429^{* * *}$ & $0.9537^{* * *}$ & $0.9429^{* * *}$ & $0.9421^{* * *}$ \\
\hline & $(0.000)$ & $(0.000)$ & $(0.000)$ & $(0.000)$ \\
\hline \multirow[t]{2}{*}{$\ln \mathrm{PM}_{2.5}$} & $0.1240^{* *}$ & $0.1771^{* * *}$ & $0.1240^{* *}$ & $0.1221^{* *}$ \\
\hline & $(0.018)$ & $(0.002)$ & $(0.018)$ & $(0.020)$ \\
\hline \multirow[t]{2}{*}{$\left(\operatorname{lnPM}_{2.5}\right)^{2}$} & $-0.0169^{* *}$ & $-0.0247^{* * *}$ & $-0.0169^{* *}$ & $-0.0166^{* *}$ \\
\hline & $(0.027)$ & $(0.003)$ & $(0.027)$ & $(0.031)$ \\
\hline \multirow[t]{2}{*}{$\operatorname{lnLS}$} & $-0.0162^{* * * *}$ & $-0.0122^{* * *}$ & $-0.0162^{* * *}$ & $-0.0171^{* * *}$ \\
\hline & $(0.001)$ & $(0.001)$ & $(0.001)$ & $(0.001)$ \\
\hline \multirow[t]{2}{*}{$\ln T I$} & & $-0.0264^{* * *}$ & $-0.0122^{* *}$ & $-0.0120^{*}$ \\
\hline & & $(0.007)$ & $(0.049)$ & $(0.055)$ \\
\hline \multirow[t]{2}{*}{$\operatorname{lnGR}$} & & & -0.0113 & -0.0072 \\
\hline & & & $(0.535)$ & $(0.722)$ \\
\hline \multirow[t]{2}{*}{$\operatorname{lnGDP}$} & & & & -0.0025 \\
\hline & & & & $(0.730)$ \\
\hline $\mathrm{AR}$ & 0.0000 & 0.0000 & 0.0000 & 0.0000 \\
\hline AR (2) & 0.9227 & 0.9200 & 0.9227 & 0.9231 \\
\hline Sargan test & 0.6440 & 0.5215 & 0.6440 & 0.6273 \\
\hline
\end{tabular}

\section{Conclusions and implications}

This paper studies whether labour supply is a mediator in the process of haze pollution affecting urban shrinkage. Panel data of 234 cities in China from 2011 to 2018 is used to measure the urban shrinkage index. $\mathrm{PM}_{2.5}$ is used as an indicator of haze pollution, and labour supply is the mediator, and the dynamic panel model is used for research.

342 The conclusions are as follows:

343 (1) Hypothesis 1 is verified by constructing a dynamic model, that is, haze 344 pollution increases the degree of urban shrinkage; (2) By constructing a mediating 
model, and we verify Hypothesis 2. That is, labour supply plays a regulatory role in the process of haze pollution affecting urban shrinkage; (3) For the control variables, the proportion of tertiary industry, urban greening and economic development can slow down urban shrinkage.

Based on our conclusions, our proposed policy suggestions are as follows:

First, local governments at all levels should increase their awareness of haze prevention and strengthen their evaluation of haze pollution. Although the haze pollution in Chinese cities has been reduced, it still occurs, especially in autumn and winter. Therefore, local governments at all levels should strengthen the prevention of haze pollution and incorporate the prevention and control of haze pollution into their routine work. Additionally, the assessment of haze pollution by local governments should be included in the assessment of local government officials so that local governments can implement effective haze pollution control.

Second, governments should strengthen cooperation between cities. Haze pollution has spatial spillover (Liu X H, 2018). Therefore, cities must communicate with each other and cooperate to establish a regional cooperative prevention and control platform, for example, the development of control plans, the establishment of environmental protection regulations, and regulations between regions. In addition to the cooperation between cities with severe haze pollution, for example, Beijing, Tianjin, and Hebei, the cities with better environmental quality in the South can also conduct "South-South cooperation" to ensure the continuous maintenance of excellent air quality. "North-South cooperation" would also be helpful. Southern cities with good air quality can share their experiences with northern cities to help northern cities improve their air quality.

Third, governments should adopt scientific and technological methods to control haze pollution, and China is implementing a strategy of scientific and technological innovation. Studies have shown that haze pollution is closely related to automobile exhaust, coal, and other energy consumption (Liu X H, 2021); thus, for example, automobile exhaust can be controlled by policy that promotes scientific and technological means. Additionally, through publicity and other means, the public 
should be encouraged to use public transportation much as possible to reduce the use of private cars and automobile exhaust emissions. The Chinese government should also continue to develop clean energy and realise energy substitution.

Fourth, governments should assess urban shrinkage and conduct scientific planning. In China, urban regional planning has always been growth oriented, and urban planners have rarely considered urban shrinkage. As aforementioned, the term "Shrinking Cities" was first explicitly proposed in China's official documents in 2019. Therefore, planners must recognise the reality of China's urban shrinkage and realise planning policies, means, and tools consistent with urban shrinkage and formulate specific corresponding countermeasures to the urban shrinkage in the context of local conditions. Some shrinking cities can follow the trend and make institutional innovations based on the local economic reality to improve R\&D and human capital investment. Additionally, technological innovation should be used to promote the transformation and upgrading of the industrial structure and improve the driver of urban economic growth. For shrinking cities with fragile ecological environments, vacant land should be transformed through ecological restoration to improve the ecological environment, demolishing outdated buildings, and building public leisure squares to enrich the quality of life of urban residents. These measures can improve the working and living conditions of residents and attract the inflow of foreign residents, alleviating urban shrinkage.

Fifth, each city should establish a strategy of strengthening the city with talent. A decrease in the labour supply will increase the degree of urban shrinkage. That is, high-quality, high-tech talent has the means to pay more attention to their health than the lower-wage workforce; thus, the former leverages its advantages and is more likely to flow out and strengthen the degree of urban shrinkage. Therefore, to slow the degree of urban shrinkage, talent must be retained by and attracted to a city. To achieve this objective, governments can implement measures to reduce the pressure of work and life for high-quality and high-tech talents, to make them have a sense of belonging to the city and curb their outflow. Additionally, governments should actively promote preferential policies such as wages and incentives to introduce talent. 
405 Other methods to optimise the investment environment and reduce taxes to attract

406

407

408

409

410

411

412

413

414

415

416

417

418

419

420

421

422

423

424

425

426

427

428

429

430

431

432

433

434

more high-quality labour while attracting capital inflow should be researched. Only

by maintaining sufficient labour resources, especially high-quality talent, can a city be full of vitality and restrain urban shrinkage.

Ethics approval and consent to participate

Not applicable

\section{Consent for publication}

Not applicable

\section{Competing interests}

The authors declare no conflict of interest.

Availability of data and materials

Not applicable

\section{Author Contributions}

Not applicable

\section{Funding}

This research is sponsored by the Philosophy and society project of universities in Jiangsu Province (2020SJA0492).

\section{References}

Akimoto, H. 2003.Global air quality and pollution. Science 302: 1716-1719.

Baron, R., M. and D., A. Kenny.1986. Themoderator-mediator variable distinction in social psychological research: conceptual, strategic, and stastical consideration. $J$. Pers. Soc. Psychol 51:1173-1182.

Blundell, R., and S. Bond.1998.Initial conditions and moment restrictions in dynamic panel data models. J. Econom. 87 (1): 115-143.

Chen, J. Huang, J. Zheng, L. Zhang, C. 2019. An empirical analysis of telecommunication infrastructure promoting the scale of international service trade: based on the panel data of countries along the belt and road. Transform. Bus. Econ 18 (2): 124-139.

Chen, J. Wang, B. Huang, S. Song, M. 2020. The influence of increased population 
density in China on air pollution. Science of the Total Environment, 735: 139456.

Cheng, K. 2016. Spatial overflow effect of haze pollution in China and its influencing factors. Nature Environment and Pollution Technology 15(4): 1409-1416.

Dong, F. Zhang, S. Long, R. et al. 2019. Determinants of haze pollution: An analysis from the perspective of spatiotemporal heterogeneity. Journal of Cleaner Production 222: 768-783.

Dubey, R. Gunasekaran, A. Childe, S., J. Papadopolous, T. Helo, P. 2019. Supplier relationship management for circular economy: influence of external pressures and top management commitment. Manag. Decis. 57 (4SI): 767-790.

Fang, X. Li, R. Xu, Q. et al. 2016. A two-stage method to estimate the contribution of road traffic to $\mathrm{PM}_{2.5}$ concentrations in Beijing, China. International Journal of Environmental Research \& Public Health 13(1): 124.

Feng, Y, Huang, X. Sun, H, et al. 2015. Framingham risk score modifies the effect of $\mathrm{PM}_{10}$, on heart rate variability. Science of the Total Environment 523:146-151.

Friedlander, S., K. and W., H. Marlow. 1977. Smoke, dust and haze: Fundamentals of aerosol behavior. Physics Today 30(9): 58-59.

Lee, J., Y. 2015.Long-term trends in visibility and its relationship with mortality, air-quality index, and meteorological factors in selected areas of Korea. Aerosol \& Air Quality Research 2015, 15(2): 673-681.

Li, M., and L. Zhang 2014.Haze in China: Current and future challenges. Environmental Pollution 189(12): 85-86.

Li. L. Qian, J. Ou, C., Q, et al. 2014. Spatial and temporal analysis of Air Pollution Index and its timescale-dependent relationship with meteorological factors in Guangzhou, China, 2001-2011. Environmental Pollution 190(7): 75.

Liu, H. Fang, C. Zhang, X. et al., 2017. The effect of natural and anthropogenic factors on haze pollution in Chinese cities: A spatial econometrics approach. Journal of Cleaner Production 165: 323-333.

Liu, X., H. 2018. Dynamic evolution, spatial spillover effect of technological innovation and haze pollution in China. Energy \& Environment 29(6): 968-988.

Liu, X., H. Zhao., T. Chang, C-T., Fu, C., J. 2021. China's renewable energy strategy 
and industrial adjustment policy. Renewable Energy 170: 1382-1395.

MacKinnon, D., P. Krull, J., L. Lockwood, C., M. 2000. Equivalence of the mediation, confounding and suppression effect. Prev. Sci 1 (4): 173-181.

Martinez, F., C. Weyman, T. Fol, S. et al. 2016. Shrinkage cities in Australia Japan, Europe and the USA: From a global process to local policy responses. Progress in Planning 105: 1-48.

Mazeikis, A. 2013. Urbanization influence on meteorological parameters of air pollution: vilnius case study. Baltica 26(1): 51-56.

Murdoch, III. 2018. Specialized vs. diversified: The role of neighbourhood economies in shrinkage cities. Cities $75: 30-37$.

Oswalt, P. Rieniets, T. Schirmel, H. et al. 2006.Atlas of shrinkage cities. International Journal of Unban \& Regional Research 36(2): 213-225.

Quah, E., and T., L.Boon. 2003. The economic cost of particulate air pollution on health in Singapore. Journal of Asian Economics 14(1): 73-90.

Reckien, D., and F. C. Martinez. 2011. Why Do Cities Shrink? European Planning Studies 19(8): 1375-1397.

Reis, J., P, Silva, E., A. Pinho, P. 2015.Spatial metrics to study urban patterns in growing and shrinkage cities. Urban Geography 37(2): 246 - 271.

Roodman, D. 2009. How to do xtabond2: an introduction to Difference and system GMM in Stata. STATA J. 9: 86-13.

Schilling, J., and J. Logan. 2008. Greening the rust belt: A green infrastructure model for right sizing America's shrinkage cities. Journal of the American Planning Association 74(4): 451- 466.

Shi, H. Wang, Y. Chen, J. et al. 2016. Preventing haze crises in China and globally. Journal of Cleaner Production 112: 1261-1271.

Tai, A., P. Mickley, L., J. Jacob, D., J. 2010. Correlations between fine particulate matter ( $\left.\mathrm{PM}_{2.5}\right)$ and meteorological variables in the United States: Implications for the sensitivity of $\mathrm{PM}_{2.5}$ to climate change. Atmospheric Environment 44(32): 3976-3984.

Van Donkelaar, A. Martin, R., V. Brauer, M. et al. 2010.Global estimates of ambient 
495 fine Particulate Matter concentrations from satellite-Based aerosol optical depth:

496 Development and application. Environmental Health Perspectives 118(6): 847-855.

497 Whiteman, C., D. Hoch, S., W. Horel, J., D. et al. 2014. Relationship between 498 particulate air pollution and meteorological variables in Utah's Salt Lake Valley. $499 \quad$ Atmospheric Environment 94: 742- 753.

$500 \mathrm{Xu}, \mathrm{B}$. , and B. Lin. 2016.Regional differences of pollution emissions in China: 501 Contributing factors and mitigation strategies. Journal of Cleaner Production 502 112(4): 1454-1463.

503 